\title{
ZAČETKI DOPOLNILNEGA POUKA SLOVENSKEGA JEZIKA IN KULTURE V NEMČIJI V 20. STOLETJU
}

\author{
Marijanca Ajša VIŽINTIN'
}

COBISS 1.02

\section{IZVLEČEK}

Začetki dopolnilnega pouka slovenskega jezika in kulture v Nemčiji v 20. stoletju Članek se ukvarja z organiziranim dopolnilnim poukom slovenskega jezika in kulture, ki se je med slovenskimi izseljenci in izseljenkami v Nemčiji začel pred skoraj sto leti. Prvi tečaji so bili organizirani že $v$ obdobju med prvo in drugo svetovno vojno, ponovno pa vzpostavljeni po podpisu bilateralne pogodbe med Nemčijo in Jugoslavijo (1968). Avtorica poudarja, da so poleg ugodnih političnih, družbenih in ekonomskih razmer v izvorni in ciljni državi za ohranjanje maternega jezika in ustanavljanje društev nujni posameznice in posamezniki, ki premagujejo birokratske ovire ter omogočajo organizacijo in izvajanje dopolnilnega pouka.

KLJUČNE BESEDE: Slovenke, Slovenci v Nemčiji, dopolnilni pouk slovenščine, ekonomski migranti

\section{ABSTRACT}

The Beginnings of Mother Tongue Lessons of Slovenian Language and Culture in Germany in the Twentieth Century

This paper focuses on mother tongue lessons of Slovenian language and culture in Germany, which began almost one hundred years ago. They were first organized between World War I and World War II and later re-established after the signing of the bilateral agreement between Germany and Yugoslavia (1968). While favorable political, social, and economic circumstances in the country of origin and in the country of destination are important, the paper emphasizes that individuals are crucial. Individuals overcome bureaucratic obstacles and enable the beginning and implementation of mother tongue lessons of Slovenian language and culture for Slovenian emigrants. KEYWORDS: Slovenians in Germany, Slovenian mother tongue and culture lessons, economic migrants

Dr. znanosti na področju poučevanja; znanstvena sodelavka, ZRC SAZU, Inštitut za slovensko izseljenstvo in migracije, Novi trg 2, SI-1000 Ljubljana; marijanca-ajsa.vizintin@zrc-sazu.si; pridr. prof., Univerza v Novi Gorici; https://orcid.org/0000-0001-5463-8796. 


\section{UVOD $^{1}$}

Finančna, materialna in organizacijska podpora dopolnilnega pouka slovenskega jezika in kulture v 21. stoletju ni edinstven pojav samostojne Republike Slovenije. Skoraj stoletni neprekinjeni proces je prekinila druga svetovna vojna, po njej pa negotovi čas, zaznamovan s prisilnimi migracijami in z vzpostavljanjem novih državnih meja. Prve tečaje slovenščine so na severu Nemčije, na katero se osredotoča pričujoči prispevek, organizirali že $v$ času med prvo in drugo svetovno vojno, sprva v samoorganizaciji nemškega duhovnika Božidarja Tensunderna, pozneje s podporo Kraljevine Jugoslavije (Tensundern 1973; Werner 1985; Drnovšek 2012). Pouk je bil ponovno vzpostavljen $v$ času federativne ljudske Republike, pozneje Socialistične federativne republike Jugoslavije ( $v$ nadaljevanju: Jugoslavije) v drugi polovici 20. stoletja. Nemčija in Jugoslavija sta leta 1968 podpisali sporazum o zaposlovanju in varstvu delavcev in delavk. Ti so v Nemčijo odhajali kot zdomci, zdomke (delavci, delavke na začasnem delu $v$ tujini), a se je začasnost za večino prevesila $v$ večdesetletno izseljenstvo ali trajno izselitev (Štumberger 2005; Brunnbauer 2009; Toš 2014; Vižintin 2016; Wörsdörfer 2017).

$\mathrm{Na}$ izseljevanje in povezovanje ter organizirano delovanje - tako v izvorni kot ciljni državi - vplivajo številni politični, ekonomski in družbeni vidiki (Lukšič Hacin 2018). Večji (ekonomski) selitveni tokovi, organizirani in spodbujani z bilateralnimi sporazumi, so v tujini vplivali tudi na večje število (novo)ustanovljenih društev, organizirani dopolnilni pouk slovenščine in ustanavljanje slovenskih katoliških misij. Podpora izvorne države in uradna naklonjenost države priselitve nista dovolj. Potrebujemo iznajdljive in vztrajne slovenske izseljenke, izseljence, ki so pripravljeni del svojega zasebnega življenja posvetiti ohranjanju slovenskega jezika in kulture. Kot primer navajam Slovensko kulturno-športno društvo Drava Augsburg (v nadaljevanju društvo Drava Augsburg). S podobno mislečimi sta ga leta 1979, ko so se njune bivanjske razmere v Nemčiji izboljšale, ustanovila Jana in Franc Kolman. ${ }^{2} \mathrm{Z}$ ustanovitvijo društva se je začel izvajati tudi dopolnilni pouk slovenskega jezika in kulture. Oboje leta 2021 v Augsburgu še vedno deluje.

1 Prispevek je nastal v okviru raziskovalnega programa »Narodna in kulturna identiteta slovenskega izseljenstva v kontekstu raziskovanja migracij« (P5-0070) in temeljnega raziskovalnega projekta "Socialna, gospodarska in kulturna zgodovina slovenskega izseljenstva« (1945-91) (J5-8246), ki sta ga financirala Javna agencija za raziskovalno dejavnost RS in Ministrstvo za izobraževanje, znanost in šport RS.

2 Življenjska zgodba Jane in Franca Kolman je bila posneta v okviru projekta »Socialna, gospodarska in kulturna zgodovina slovenskega izseljenstva (1945-91)«; celotno življenjsko zgodbo glej v: Milharčič Hladnik, Vižintin (2020: 308-340). 


\section{SLOVENSKO IZSELJEVANJE IN ORGANIZIRANOST V NEMŠKIH DEŽELAH NA ZAČETKU 20. STOLETJA}

Izseljevanje iz slovenskih dežel proti nemškim je bilo organizirano že v Avstro-Ogrski (Kalc, Milharčič Hladnik, Žitnik Serafin 2020), izseljevali so se predvsem revnejši prebivalci, prebivalke Štajerske in Kranjske. Odhajajoče iz Trbovelj, Hrastnika, Zagorja so vodili nemški agenti; odhajali so v dveh valovih (1880-1888 in 1903-1906) in se v Nemčiji strnjeno naseljevali (Drnovšek 2012: 139-184).

Prvi priseljenci so prišli že $v$ osemdesetih letih preteklega stoletja in najstarejši slovenski rudar, ki ga zasledimo v obdelanem gradivu, se je zaposlil kot kopač v kraljevem rudniku pri Wanne-Eickel leta 1878. [...] Često so izseljenci odšli v Nemčijo s trdnim namenom, da se po določenem času s prihranjenim denarjem vrnejo $v$ domovino in si doma kupijo kmetijo. Nekateri so porabili prihranjeni denar za pot $v$ ZDA, kamor so sledili sorodnikom in znancem, večinoma pa so ostali v Nemčiji in le malo jih je uresničilo svoj prvotni namen. (Werner 1985: 72)

Sezonski delavke in delavci, ki so organizirano odhajali iz Prekmurja, so se zaposlovali v kmetijstvu. Okoli 25.000 izseljenih Slovenk, Slovencev v Porurju je leta 1899 prvi uradno obiskal Janez Evangelist Krek. Prvo slovensko pevsko društvo z imenom Ilirija je bilo leta 1898 ustanovljeno v kraju Essen-Borbeck. Društva so bila liberalno in narodnjaško usmerjena, političnih ambicij ( $v$ nasprotju s poljskimi) niso imela. $\mathrm{Na}$ prehodu v 20. stoletje so sledile ustanovitve katoliških društev sv. Barbare; pred prvo svetovno vojno je bilo avstrijskih in slovenskih društev 42 (Werner 1985: 120).

Prva tečaja slovenskega jezika je nemški duhovnik Božidar Tensundern, ki se je naučil slovensko, leta 1926 organiziral v Gladbecku, in sicer "popoldne ob 16. uri dvakrat na teden« kar v svojem stanovanju, leta 1927 pa v Meerbecku (Tensundern 1973: 38). Otroke je učil peti slovenske pesmi, organiziral je izlete $v$ domovino in javne dogodke v slovenskem jeziku: dogodka v Gladbecku se je leta 1928 udeležilo do 500 ljudi, med njimi največ Slovencev. O tem so pisali tako nemški kot slovenski časniki v domovini (Tensundern 1973: 40; Drnovšek 2012: 156). Slovenska šola za vestfalske Slovence, ki so bili skoraj »vsi rudarji« (Tensundern 1973: 9; Werner 1985: 81; Drnovšek 2012: 146), je bila tako priljubljena, da so otroci, ker ni bilo dovolj stolov, sedeli kar na tleh. Včasih so manjkali pri drugih obveznostih, kar je pri nekaterih povzročalo skrbi, a Božidar Tensundern je z nemškega ministrstva za prosveto dobil uradni odgovor in zahvalo za svoje delovanje. Podporo pri organizaciji slovenske šole je nemško ministrstvo za prosveto izrazilo na podlagi njihovih izkušenj z organizacijo šol za nemške izseljence v Braziliji: ${ }^{3}$

3 Med letoma 1800 in 1950 se je v Brazilijo priselilo okoli pet milijonov ljudi, med njimi dva milijona iz Portugalske, 1,5 milijona iz Italije, 600.000 iz Španije, 300.000 iz Nemčije in 190.000 z Japonske (Knauf 2010: 147). 
Martin Jazbec iz Bauer-Scholvena je prosil svojega učitelja, naj mu oprosti dve zamujeni uri, da se bo mogel udeležiti pouka v slovenski šoli v Gladbecku. Učitelj se je začudil in celo ustrašil in kar ni mogel verjeti, da bi bila slovenska šola sredi Nemčije! Kako je to mogoče? Takoj je vprašal ministrstvo prosvete v Berlinu, kako je s slovensko šolo v Gladbecku. Prosvetni minister pa je meni odgovoril: »Hvaležni smo vam, da skrbite za slovenske otroke in jih učite materinega jezika. Nemci imamo v Braziliji nemške šole za nemške otroke.« (Tensundern 1973: 38-39)

Božidar Tensundern ni edini prepoznaval, da otroci slovenskih staršev »naglo pozabljajo materinščino,« nekateri pa slovenščino »samo še lomijo« (Drnovšek 2012: 148, 155). Dejavnosti za ohranjanje jezika, povezovanje in društveno delovanje je spodbujala tudi Kraljevina Jugoslavija. Društva je upravljal Jugoslovanski izseljeniški odbor, delila pa so se na dve struji: Zveza jugoslovanskih katoliških društev je leta 1938 štela 34 društev, Zveza jugoslovanskih delavskih in podpornih društev pa 52 društev, od tega 16 ženskih; tretja možnost so bila društva, naklonjena avstrijskemu duhu.

K odprtju slovenskih izseljenskih knjižnic v Porurju je najbolj pripomogel izseljenski komisar Đuro Berislav Deželić: leta 1931 so bile glavne knjižnice v krajih EssenStoppenberg, Gladbeck, Moers-Meerbeck in Düsseldorf. Deželić je »v Beogradu predlagal, da bi se organizirali stalni enoletni tečaji« za otroke in odrasle (Drnovšek 2012: 155). In res so leta 1931 pod okriljem Kraljevine Jugoslavije v Nemčiji organizirali osem tečajev slovenščine: v Gladbecku dva, v krajih Homberg-Hochheide, Marl, Moers-Meerbeck, Osterfeld, Recklinghausen-Suderwich in Gerthe po enega. Tečaje je obiskovalo 173 otrok. Tečaje so vodili člani Jugoslovanskega katoliškega društva Franjo Pokovec, Valentin Kovač, Mihajlo Zupanc, Franjo Čebin, Ivan Lindič, Rudolf Povše, Franjo Čater in Jakob Šteh, iz Jugoslovanskega delavskega in podpornega društva pa Ivan Mažgon, Avgust Korošec, Franjo Mlakarn in Josip Kučnik (Deželić v Drnovšek 2012: 158). V Porurju je bilo mogoče kupiti tri slovenske časopise: Naš zvon, ki je predstavljal katoliško in liberalno smer, Rafael, ki je bil čisto cerkveno usmerjeni časopis, ter Domovino, ki je bila podobna nemškemu časopisu Der Landbote (Werner 1985: 128).

Od maja 1938 do konca druge svetovne vojne je nacistična oblast tečaje slovenščine prepovedala, prekinjeno je bilo tudi društveno delovanje. Po drugi svetovni vojni so se Slovenke, Slovenci razselili v druge evropske države, v Severno Ameriko, nekateri so se vrnili v domovino, le malo jih je ostalo (Tensundern 1973: 11; Werner 1985: 113). ${ }^{4}$ Društveno življenje je »prenehalo - vse je postalo tiho in mirno - nastala je huda borba za vsakdanji kruh, stanovanje, delo«. Po vojni »so prihajali v

4 Podobno so se razselili tudi drugi, npr. Poljakinje, Poljaki že v dvajsetih letih 20. stol. Tretjina se je vrnila na Poljsko, tretjina se je izselila v Francijo, Belgijo ali v ZDA (Werner 1985: 10, 11). Nemčija, iz katere je zaradi krize leta 1923 odšlo tudi 115.000 Nemk in Nemcev, je ostala država izseljevanja in priseljevanja. Nizozemska, ki je bila med prvo svetovno vojno nevtralna, je bila cilj deset tisočim izseljenim iz Nemčije, mlada dekleta so se zaposlovala kot služkinje; množično pa so se priseljevali iz Poljske, Rusije (Drnovšek 2012: 142). 
Nemčijo Slovenci na >črnos, pozneje pa so prihajali legalno kot delavci (Gastarbeiter) rudarji, trgovci, natakarji, bolničarke, otroške negovalke, rokodelci, uradniki, inženirji, zdravniki,« je zapisal Božidar Tensundern (1973: 165-167).

\section{SLOVENSKE IZSELJENKE, IZSELJENCI V DRUGI POLOVICI 20. STOLETJA IN SKRB DOMOVINE ZANJE}

Migracije iz slovenskega prostora so po drugi svetovni vojni sprva zaznamovali begunke in begunci, pregnane in razseljene osebe. Poleg oseb slovenskega so bile med njimi tudi osebe nemškega in italijanskega izvora, hkrati pa so se v Slovenijo postopno vračali deportirani in izgnani (Lukšič Hacin 2018: 62). Kompleksnost migracijskih procesov ponazarja

primer povojnih beguncev v avstrijskih taboriščih, ki so pozneje odšli v Avstralijo, [in] pokaže, kako je posameznik Slovenijo zapustil iz t. i. političnih razlogov, v Avstralijo pa je prišel iz ekonomskih razlogov, ter obratno, ko so številni t. i. prebežniki iz druge polovice petdesetih let 20 . stoletja odhajali z namenom zaposlovanja, a so bili zaradi nelegalnega prehoda meje kar nekaj časa razumljeni kot del politične emigracije. (Lukšič Hacin 2018: 67)

Nezakonito izseljevanje pred letom 1963, ko je Jugoslavija uradno odprla meje, se je legaliziralo z meddržavnimi sporazumi in povečevalo do leta 1973. Sporazume o zaposlovanju in varstvu delavk, delavcev je Nemčija z Italijo podpisala leta 1955, s Španijo in z Grčijo leta 1960, s Turčijo leta 1961, z Marokom leta 1963, s Portugalsko in Tunizijo leta 1965 (Leggewie 2010: 242). Jugoslavija je med letoma 1950 in 1979 podpisala 17 dvostranskih sporazumov o socialni varnosti. Na njihovi podlagi je bilo zaposlovanje $v$ drugih državah ne le legalno, ampak tudi organizirano: s Francijo, z Luksemburgom, Belgijo, Nizozemsko, s Češkoslovaško, z Madžarsko, Bolgarijo, Veliko Britanijo, s Poljsko, z Italijo, s Švico, z Avstrijo, s Švedsko, z ZR Nemčijo, Nemško demokratično republiko, Norveško, Dansko (Svetek 1985: 21-31). Z Nemčijo je bil sporazum podpisan leta 1968, veljati pa je začel leta 1969. Preden so migracije postale večinsko ekonomske in zakonite, so bile zaznamovane s prebežništvom; to izpričujejo tudi osebne življenjske zgodbe prebežnic, prebežnikov (Japelj Carone 2016; Milharčič Hladnik 2020):

Čeprav je treba migracije vedno razumeti $v$ širšem socialnem, kulturnem in političnem kontekstu, pa lahko o kompleksnosti vzrokov in motivov ter o načinih odhajanja mladih največ izvemo iz osebnih pričevanja akterjev povojnih migracij na Slovenskem. Mladih ne smemo videti (zgolj) kot žrtve povojnih okoliščin, pač pa kot aktivne akterje in avtonomne odločevalce. Razlogi [...] so bili zunanji, a hkrati osebni in intimni; odločitve hipne ali premišljene; odhodi pa dolgo načrtovani ali zgolj korak v neznano. (Milharčič Hladnik 2020: 163) 
Ekonomske migracije proti Nemčiji, ki so se v drugi polovici 20. stoletja preselile na njen jug, so bile najprej poimenovane zdomstvo, šele pozneje izseljenstvo. Močan tok zaposlovanja $v$ tujini se je »namesto $v$ nameravano nekajletno preselitev pogosto prevesil v večletno ali tudi trajno (Zupančič 2001: 293). Leta 1951 je bila v Jugoslaviji ustanovljena Slovenska izseljenska matica, ki je do leta 2011 sodelovala pri organizaciji več kot tisoč gostovanj slovenskih kulturnih skupin v Sloveniji in po vsem svetu (Rogelj 2011). Leta 1953 je prvič izšel letni zbornik Slovenski izseljenski koledar, ${ }^{5}$ leta 1954 so začeli izdajati mesečnik Rodna gruda. Za informiranje slovenskih zdomk, zdomcev so v Sloveniji izhajali posebni časopisi, nemške in belgijske radijske postaje pa so zanje oddajale poseben program. Skrb za slovenske izseljenke, izseljence in zdomke, zdomce je prevzela Socialistična zveza delovnega ljudstva (SZDL), v kateri je deloval Koordinacijski odbor za vprašanja naših delavcev na začasnem delu tujini. Leta 1975 je v Nemčiji delovalo pet društev (Olaj, Rupnik 1975), leta 1984 pa 28 društev z eno koordinacijo (Šabjan 1984). ${ }^{6}$ Za društva oz. klube so skrbele tudi organizacije SZDL iz posameznih slovenskih občin, društvo Triglav Stuttgart npr. »je uspešno sodelovalo od leta 1976 do leta 1990 z občino Kranj, nato pa z občino Maribor« (SKUD Triglav Stuttgart ... 2000: 18).

Slovenska društva v Zahodni Evropi so se med seboj povezovala in srečevala. O podpori iz Jugoslavije in izjemnem programu priča opis srečanja leta 1978 (Pogačnik idr. 1978: 38): na 6. srečanju slovenskih društev Zahodne Evrope 10. junija 1978 v Frankfurtu so bogat program začela športna tekmovanja (kegljanje, šah, namizni tenis). Sledil je kviz "Spoznavajmo svet in domovino", ob katerem so nastopili ansambel Mojmirja Sepeta, Majda Potokar, Miha Baloh in Janez Hočevar - Rifle. Po prevzemu listine o sodelovanju in kulturnem programu slovenskih društev iz Zahodne Evrope je na zabavi s plesom igral Plesni orkester RTV Ljubljana, peli so: Majda Sepe, Marjana Deržaj, Braco Koren, Janko Ropret, dirigiral je Jože Privšek. Program je spremljala razstava slovenskih knjig, umetniških del, ročnih del, prodajali so spominke, poskrbljeno je bilo za otroško varstvo in zdravniško službo.

Za slovenske izseljenke, izseljence je pred drugo svetovno vojno in po njej skrbela tudi slovenska Katoliška cerkev. Leta 1960 je bila v Stuttgartu ustanovljena prva povojna slovenska župnija v Nemčiji, prvega binkoštnega srečanja v Derendingenu pri Tübingenu se je 14. maja 1967 udeležilo 400-500 ljudi (Vižintin 2016). Slovenski

5 Slovenski izseljenski koledar je prvič izšel novembra 1953 (za leto 1954) kot naslednik Ameriškega družinskega koledarja, ki je v Združenih državah Amerike izhajal med letoma 1915 in 1950.

6 Koordinacijski odbor slovenskih društev Stuttgart, Triglav Stuttgart, Triglav Reutlingen, Triglav Nagold (Reutlingen), Kajuh Uhingen (Gammelshausen), Slovenija Ulm-Donau, Planina Ludwigsburg, Mura Besigheim in Heilbronn-Böckingen, Planinka Ravensburg, Zlatorog Schwäbisch Gmünd in Ruppertscofen, France Prešeren Mannheim, Triglav München, Lastovka Ingolstadt, Drava Augsburg, Slovensko kulturno društvo Erlagen, Simon Jenko Nürnberg, Sava Frankfurt, Bled Essen, Celje Grevenbroich, France Prešeren Burscheid, Maribor Hilden, Ljubljana Essen, Slovenski zvon Krefeld, Ljubljana Leverkusen, Slovenija Gütersloh, Rudar Dortmund, Slovenska beseda Hückelhoven, Slovenija Berlin (Šabjan 1984: 6-8). 
župniji v Münchnu in Stuttgartu sta svoj pouk slovenščine, vrtec in dejavnosti (Bečan 2004; Štrubelj 2012: 24-25) organizirali še preden so se začela s podporo Jugoslavije ustanavljati društva in so bili v Nemčijo napoteni prvi učitelji, učiteljice t. i. slovenske šole. Maja 1973 so $v$ Nemčij slovenski duhovniki delovali v dvanajstih krajih (Tensundern 1973: 167-169). Duhovnike je povezovala Zveza slovenskih izseljenskih duhovnikov, vernike in vernice pa revija Naša luč. Najpomembnejša naloga duhovnikov in redovnic je bila skrb za evangelizacijo in podeljevanje zakramentov, ustanavljali pa so tudi jezikovne tečaje, slovenske knjižnice, revije, reševali socialne probleme in organizirali družabne prireditve.

Ko je leta 1973 Nemčijo zajela gospodarska kriza, je z odlokom prepovedala zaposlovanje tujih delavk, delavcev. ${ }^{7}$ Migracije so v obdobju 1974-1979 stagnirale, število priseljenih pa se ni zmanjšalo; nasprotno, s prenehanjem kroženja so se $v$ Nemčijo priselile družine. V Baden-Württembergu so bili leta 1977 jugoslovanski delavci, delavke in njihove družine skupaj s turškimi najštevilčnejša priseljenska skupina (Slavec 1982: 61).

\section{Slovenska šola: Od podpore iz domovine do angažiranosti posameznic, posameznikov}

Po letu 1970, ko so se v Nemčiji (in drugod) množično ustanavljala slovenska društva, ${ }^{8}$ se je pospešeno organiziral tudi dopolnilni pouk slovenščine. Leta 1971 je bil v Stuttgart napoten učitelj Franc Sedmak, štiri leta pozneje so v Baden-Württenbergu poučevale štiri učiteljice: Dragica Nunčič, Milica Pukl, Marija Kurent in Marija Stermecki; v Berlinu je poučevala Milena Skrt, v Münchnu Martina Vizjak, v Frankfurtu Romana Dolanc (Olaj, Rupnik 1975: 54-56). Jugoslavija »je skrbela glede njihovega bivanja v tujini, zlasti glede tega, da so bili čim bolj vezani na domovino. Skrbeli sta jih predvsem asimilacija in odtujitev, zato so podpirali izobraževanje zdomcev, predvsem njihovih otrok v maternem jeziku« (Čepič 2010: 410), slovenska dopolnilna šola je postala prostor srečevanj ter priložnost za nova poznanstva in stike. Leta 1978, ko je v Nemčiji delovalo 16 društev in je dopolnilni pouk slovenščine izvajalo 14 učiteljic,

7 Prelomnica je poudarjena tudi v Nemškem muzeju izseljevanja, ki obravnava zadnjih 300 let nemškega izseljevanja in priseljevanja. V prvem delu razstave so predstavljene življenjske zgodbe, izbrane med 7,2 milijona ljudmi, ki so med letoma 1830 in 1974 zapustili pristanišče Bremerhaven. Leta 1973 so naslovnice časopisov oznanjale, da je Nemčija zaprla meje gostujočim delavkam, delavcem. Nemčija je znana kot dežela priseljevanja, a se iz nje tudi izseljujejo: v 21. stoletju se iz nje vsako leto izseli okoli $100.000 \mathrm{Nemk}$, Nemcev. Zaposlujejo se v Švici, Skandinaviji, Avstriji, ZDA in Avstraliji (Eick 2017: 6, [96-97]).

8 Slovenska društva, ki so se osamosvajala izpod okrilja jugoslovanskih društev, so se ob srečanjih predstavila v priložnostnih publikacijah, 8. srečanja v Frankfurtu (1978) se je npr. udeležilo 16 društev iz Nemčije, pet iz Francije, po tri iz Belgije in Nizozemske, po dve iz Švice in Avstrije, 11 iz Švedske (Pogačnik idr. 1978). 
učiteljev, ${ }^{9}$ je v deželi Baden-Württenberg pouk obiskovalo 517 otrok (Pogačnik idr. 1978: 42-47; Slavec 1982: 83).

Kljub organizacijski in finančni podpori Jugoslavije društvenega delovanja in dopolnilnega pouka slovenščine ne bi bilo brez osebnega angažmaja staršev, ki so ob (napornem) vsakdanjiku svoje otroke vozili v slovensko šolo, nekateri tudi več deset kilometrov daleč. Dopolnilni pouk je bil organiziran v različnih jezikih jugoslovanskih narodov, da pa se je bilo treba za njegovo organizacijo $v$ slovenščini ponekod bolj potruditi, ponazarja primer Jane in Franca Kolmana, ki sta se iz Sevnice preselila v Augsburg. Franc Kolman se je leta 1970 odločil za pot v Nemčijo, čeprav je imel službo v Sevnici:

Kolega je slišal za Nemčijo in potem sva se odločila, da greva skupaj. To je šlo vse prek Zavoda za zaposlovanje Novo mesto. Najprej smo šli v Novo mesto na izobraževanje, pravzaprav na priprave, šest mesecev smo imeli plačano stanovanje, šolanje in hrano. Po šestih mesecih smo bili kvalificirani delavci. Eni so se šolali za strugarje, drugi za ključavničarje, varilce. V Nemčijo bi morali oditi že februarja ali marca, vendar se je zavleklo do junija, 16. 6. 1970 pa smo dobili dokumente. (Franc Kolman)

Izkušnja ekonomske migracije Franca Kolmana priča o načrtovanih in spodbujanih ekonomskih migracijah med Nemčijo in Jugoslavijo, organiziranih in vodenih preko Zavodov za zaposlovanje. Raziskava o Slovencih v Nemčiji, v kateri je leta 1974 sodelovalo tisoč izseljenih, je pokazala, da so Slovenke, Slovenci odhajali v Nemčijo predvsem z željo po izboljšanju življenjskega položaja, zaradi nizkega zaslužka in slabih stanovanjskih razmer doma, prisotni pa sta bili tudi želji po spoznavanju sveta in novih izkušnjah (Toš idr. 2014: 13). To je veljalo tudi za Franca Kolmana in njegovo ženo Jano; s hčerko se mu je v Nemčiji pridružila leta 1971. Začetki v Nemčiji so bili skromni, bivanjske razmere neustrezne: ${ }^{10}$

Stranišče je bilo na hodniku, za več strank, kopalnice ni bilo. Vodo smo si greli na štedilniku, bil je kotliček in tam smo si greli vodo za vse, kadar smo potrebovali. Tuširali in kopali smo se v majhni banji. Ingrid je spala v otroškem vozičku, ki mi ga je mama Karolina kupila v Celju. V spalnici je bila postelja, a v njej je bilo pozimi grozno: stene niso bile izolirane, po stenah je tekla voda. Streha je bila v redu, vendar ni bilo prave izolacije, v spalnici je bilo vlažno. Jaz sem bila zelo razočarana, doma smo imeli novo hišo. (Jana Kolman)

9 V Nemčiji je dopolnilni pouk slovenskega jezika in kulture leta 1978 izvajalo 14 učiteljic, učiteljev, v Avstriji trije, v Švici štirje, v Belgiji in Angliji po eden, na Švedskem 15 (Pogačnik idr. 1978: 44-47).

10 Podobno je bilo pri Slovenkah, Slovencih v Mannheimu (Slavec 1982: 69-70) in v Avstriji (Artl, Lorber 2015: 60-66). 
Leta 1977, ko so se bivanjske in ekonomske razmere Jane in Franca Kolmana izboljšale, rodila pa sta se jima že dva od treh otrok, se je okrepila želja po slovenski šoli. Najprej je bilo treba premagati birokratske ovire in ustanoviti društvo. Društvo Drava Augsburg je bilo ustanovljeno 4. maja 1979, priprave na ustanovitev pa so se začele že dve leti prej v Münchnu:

Hodila sva v administrativno šolo. Velikokrat sva se srečala tudi z učiteljico dopolnilnega pouka v Münchnu, z gospo Martino Vizjak. V Münchnu so že imeli šolo in ona je predlagala, da zberemo naslove staršev, organiziramo sestanek staršev in da se dogovorimo za slovensko šolo v Augsburgu. To nalogo sva prevzela midva. Prosila sva tudi gospoda Jožka Bucika, slovenskega župnika, ki je že imel naslove družin; on nama je posredoval veliko informacij. Vzporedno so nam svetovali s konzulata v Münchnu, da ustanovimo društvo, slovensko društvo. (Jana Kolman)

Podrobnejše zaplete pred ustanovitvijo društva je dodatno opisal Franc Kolman. V enem izmed jugoslovanskih društev je srečal gospoda llića, jugoslovanskega konzula za šolstvo, ki je obljubil ustanovitev slovenske šole.

V Augsburgu je že bila organizirana celodnevna srbohrvaška šola in dopolnilna šola srbohrvaščine. ${ }^{11}$ Tekla so leta, hči je bila v tretjem razredu, slovenske šole pa še ni bilo. Ko sem spet šel enkrat službeno na konzulat v München, niso ničesar vedeli, ker so se ljudje med tem časom zamenjali. Poslali so me naprej do drugega, ki je bil odgovoren za izobraževanje. Predlagal je, da zberemo naslove, da imamo nekaj v rokah. Pa sva res, vsem, ki sva jih poznala, sva z ženo Jano razdelila liste, da so se podpisali. Vsi so se podpisali, tudi Hrvati in Bošnjaki, tako da smo imeli več kot 100 podpisov. Potem so nam na sestanku dejali, da naj ustanovimo društvo. Mi takrat o društvu še nismo razmišljali. Pozneje smo ugotovili, zakaj društvo: naša naloga je bila, da smo hodili na občine in urade ter nagovarjali ljudi, da bi nam čim prej izdali dovoljenje za šolo. V Augsburgu je bilo veliko šol in augsburški Urad za šolstvo. Zapleteno je bilo, težava so bili prvi uradniki, ki so spraševali, kaj bomo s šolo, saj že imamo jugoslovansko šolo. Uradnike je bilo treba prepričati, da ima Slovenija svoj jezik, da slovenski jezik ni zastopan na jugoslovanski šoli. (Franc Kolman)

Jana Kolman, članica upravnega odbora društva Drava Augsburg in desna roka številnih predsednic in predsednikov med 40-letnim delovanjem društva, se zelo dobro

11 Šole $v$ maternih jezikih delavk in delavcev so bile del nemške politike do priseljenih, saj so »spodbujale pripravljenost na vrnitev/začasno družbeno integracijo/pripravljenost na odhod«; še precej bolj je bilo to očitno v odnosu do Turkinj in Turkov, najmočnejše manjšine, ki je izšla iz delovnih migracij (Bade 2005: 373-374). Nemčija, ki je bila v drugi polovici 20. stoletja izrazito priseljenska država, čeprav je to zanikala (Castles, Miller 2009: 263), je pričakovala, da se bodo nemški priseljenke, priseljenci vrnili v izvorne dežele. 
spominja tako začetka pouka, ki ga je delno financiralo mesto Augsburg, delno pa Jugoslavija, kot prvih učiteljic.

Dopolnilni pouk je na začetku obiskovalo ogromno otrok, več kot 80, imeli smo seznam s 112 otroki. Prva učiteljica je bila gospa Olga Krčmar iz Ingolstadta. Potem jo je zamenjala učiteljica Majda Bešlagič iz Kranja. Šla je od družine do družine in iskala stike. Ona je bila učiteljica dva mandata, vlado v Sloveniji smo prosili, če ji lahko podaljšajo še en mandat, ampak niso. Pozneje smo dobili gospo Nevenko Nemec, ki ni bila tu dolgo, mislim, da je bila eno leto, mogoče dve leti. $V$ Augsburgu so nam dovolili dopolnilni pouk v šolah. Pouk je potekal ob sobotah, nekaj časa je potekal med tednom, ob četrtkih, ampak ne dolgo. Največkrat je bil dopolnilni pouk ob sobotah, od 9. do 12. ure. Pripeljali smo jih starši, nekateri so vozili 20 ali celo $30 \mathrm{~km}$ daleč, da so pripeljali otroke v šolo. Bili so srečni, da je obstajala slovenska šola. Otroci so obvezno nastopali na vsaki prireditvi, ob dedku Mrazu, na prireditvah ob dnevu republike, za 1. maj, 8. marec. (Jana Kolman)

Leta 1984 je društvo Drava Augsburg z Občino Piran podpisalo listino o sodelovanju. Leta 2014, ob 35-letnici društva, so obiskali kraje po Sloveniji, iz katerih prihajajo člani društva. Z avtobusom so se odpeljali tudi v Piran, kjer jih je pozdravil takratni župan Peter Bossman in z njimi zaplesal na Tartinijevem trgu. Leta 2019, ko je društvo Drava Augsburg praznovalo 40-letnico delovanja v Nemčiji, je dopolnilni pouk slovenščine poučeval Velimir Brunski. Na slavnostni prireditvi je nastopil s svojimi učenka$\mathrm{mi}$, učenci, program pa so povezali s 33 . Folklorijado v Nemčiji delujočih slovenskih folklornih skupin (z gosti). ${ }^{12}$

Niso niti vsi starši pošiljali svojih otrok k dopolnilnemu pouku slovenščine niti niso vsi doma govorili slovensko (prim. Slavec 1982; Štumberger 2006). Vztrajanje nekaterih staršev, da otroci obiskujejo sobotno oz. slovensko šolo (ali v organizaciji katoliške misije ali v okviru dopolnilnega pouka z napotenimi učiteljicami, učitelji iz Jugoslavije, pozneje iz Slovenije), je obrodilo sadove:

Če se danes oziram nazaj, čutim veliko hvaležnost. Moji starši so se preselili v tujino. Z leti so se integrirali v nemško družbo, si ustvarili družino in nas skrbno vzgajali. Največja dota, ki sem jo od njih prejela, je moj materin [!] jezik. Vem, kako je težavno in naporno, da svojim otrokom v tujini posreduješ ne samo jezika, ampak tudi ljubezen do domovine in njene kulture. (Melita Bolčina v Bečan 2004: 35)

12 Prireditve so se udeležili tudi minister Peter Jožef Česnik, Primož llešič (Urad RS za Slovence v zamejstvu in po svetu), veleposlanik Franci But (Berlin), generalna konzulka Dragica Urtelj (München), avtorica članka, predstavnik mesta Augsburg; tokrat je bil to Jurij Heizer, namestnik župana mesta Augsburg, sam priseljen iz Rusije kot potomec nemških izseljenk, izseljencev. 


\section{POVEZOVANJE V 21. STOLETJU}

Po osamosvojitvi leta 1991 je Republika Slovenija nasledila veliko meddržavnih jugoslovanskih sporazumov, nadaljevala je tudi organizacijo in financiranje dopolnilnega pouka slovenskega jezika in kulture za slovenske izseljenke in izseljence $v$ Evropi. Slovenska društva, katoliške misije, svetovalne delavke, učiteljice in učitelji dopolnilnega pouka slovenščine so se v Nemčiji povezovali in skupaj organizirali prireditve in s tem presegali lokalno delovanje in politično opredeljenost. Nekajkrat letno so se in se še vedno srečujejo na društvenih sestankih, na sestankih južne ali severne koordinacije, na folklornih in pevskih seminarjih, na folklorijadi in posvetih (Vižintin 2016; 2017).

Leta 2019 so se v Augsburgu srečali na 33. Folklorijadi, v Langenargnu ob Bodenskem jezeru pa na 24. Posvetu slovenskih društev, katoliških misij, učiteljev, socialnih delavcev in članov folklornih skupin $v$ Nemčiji. $V$ južno koordinacijo slovenskih društev v Nemčiji je bilo leta 2019, ko jo je vodila Valerija Perša, povezanih 19 društe$v_{1}^{13} v$ severno koordinacijo, ki jo je vodil Jože Pahič, pa osem društev, od tega so tri zaprla svoja vrata. ${ }^{14}$ Skupaj je bilo leta 2019 še vedno registriranih in delujočih 24 društev (19 v južni in pet v severni koordinaciji). Društveno delovanje v 21. stoletju finančno podpira Urad Republike Slovenije za Slovence v zamejstvu in po svetu, slovenske izseljenke in izseljenci pa se od leta 2011 v Sloveniji srečujejo na prireditvi Dobrodošli doma. Leta 2017 so napoteni katoliški duhovniki delovali v desetih slovenskih katoliških misijah v krajih Augsburg, Berlin, Essen, Frankfurt, Ingolstadt, Köln, Mannheim, München, Stuttgart in Ulm (Vižintin 2017).

V šolskem letu 2019/20 je bil dopolnilni pouk slovenskega jezika in kulture organiziran v 19 evropskih državah, obiskovalo ga je okoli 1900 udeleženk in udeležencev, od tega več kot 1000 otrok. Slovenščino je poučevalo 36 učiteljic

13 Planinka Ravensburg (sedež Baindt), Slovenija Ulm, Slovenski muzikantje Sindelfingen, Kajuh Uhingen-Ebersbach (Dürnau), Štorklja Schorndorf, Triglav Reutlingen (Pliezhausen), Triglav Stuttgart, Triglav Sindelfingen, Mura Bönningheim, Slovenija Stuttgart, Planinka Radolfzell (Radolfzell am Bodensee), Lipa Tuttlingen (Dunningen), Lipa München, Lastovka Ingolstadt, Drava Augsburg (Neusäß), Sava Frankfurt (Frankfurt am Main), Geris e. V., Nürnberg, Internationaler Club Sloweniens (ICS), Bavarsko-slovensko društvo (Koordinacija slovenskih društev v južni Nemčiji 2020).

14 Jože Pahič (2020) je navedel, da so še vedno dejavna društva Maribor Hilden, Slovenski zvon Krefeld (sedež Willich), Slovenski cvet Kerken, Duplek/Slo. 1990 e. V. Dormagen-Gohr; društvo Bled Essen »trenutno ni aktivno, ni pa odjavljeno«, zato ga štejemo med delujoča društva. Društva France Prešeren Burscheid (1977-2013), Slovenska beseda Erkelenz (1981-2009) in Lipa Neuss (1977-2006) »so zaprta, ne delujejo več«; z upokojitvijo župnika Alojzija Rajka se je zaprla katoliška misija v Essnu (1958-2019). 
in učiteljev, ${ }^{15}$ od tega 14 napotenih in 22 nenapotenih. ${ }^{16}$ Dopolnilni pouk je $v$ šolskem letu 2019/20 v Nemčiji poučevalo šest učiteljic in učiteljev: Velimir Brunski (München, Kirchheim (Teck), Weingarten, Memmingen, Ingolstadt, Augsburg, Ulm), Mira Delavec Touhami (Wittnau bei Freiburg, Schwenningen (Schwarzwald), Worms, Karlsruhe, Duttenberg bei Heilbron, Pfullingen, Reutlingen, Mannheim), Vinko Kralj (Sindelfingen, Pforzheim, Stuttgart, Schömberg, Schorndorf), Magdalena Novak (Berlin), Natalija Robnik (Frankfurt), Martina Tomšič Kramberger (Hilden, Dusseldorf, Essen, Gütersloh) (Dopolnilni pouk 2019/20).

Na začetku 21. stoletja Nemčija poleg Avstrije ostaja država, ${ }^{17} v$ kateri se najraje zaposlujejo slovenske izseljenke in izseljenci, kar bo $v$ naslednjih letih verjetno pozitivno vplivalo na zanimanje za dopolnilni pouk slovenščine in spremenilo določene dejavnosti slovenskih društev $v$ Nemčiji. Vodenje društev in njihovo delovanje postopoma prevzema generacija otrok, rojenih v Nemčiji, ali nove slovenske priseljenke in priseljenci (Vižintin 2016; 2017). To se je zgodilo tudi v društvu Sava Frankfurt, v katerem je leta 2012 vodenje društva prevzel Igor Križnar, ki se je iz Slovenije v Nemčijo priselil leta 2009. Ena najpomembnejših društvenih dejavnosti je dopolnilni pouk slovenščine, ki v Frankfurtu poteka že od leta 1974.

\section{SKLEP}

Brez migracij ljudi s slovenskim maternim jezikom iz slovenskega etničnega prostora $v$ druge države ne bi bilo dopolnilnega pouka slovenščine. Ne bi ga bilo niti brez podpore izvornih dežel, tako Kraljevine Jugoslavije in Jugoslavije kot Republike Slovenije, ki so v tujino pošiljali učiteljice, učitelje in duhovnike. Predvsem pa tečajev slovenščine, slovenskih šol, dopolnilnega pouka slovenskega jezika in kulture - poimenovanja so se v zadnjih sto letih spreminjala - ne bi bilo brez (samo)organiziranja posameznic in posameznikov, ki so, da v tujini rojeni otroci ne bi pozabili slovenskega jezika in kulture, to potrebo prepoznali.

Na slovensko izseljevanje in povezovanje, organizirano delovanje $v$ društvih in dopolnilni pouk slovenščine $v$ drugih državah vplivajo številni politični, ekonomski in družbeni vidiki, ki soustvarjajo migracijske tokove. Ker so za nemške izseljenke in

15 Avstrija (2 učitelja), Belgija (1), Bosna in Hercegovina (3), Češka republika (1), Črna gora (1), Finska (1), Francija (2), Hrvaška (6), Lihtenštajn (1), Luksemburg (1), Makedonija (2), Nemčija (6), Nizozemska (1), Rusija (1), Srbija (6), Švedska (1), Švica (3), Velika Britanija (1 učiteljica), Ukrajina (0) (Dopolnilni pouk 2019/20).

16 Napotene učiteljice, učitelji so poslani v tujino s strani Zavoda Republike Slovenije za šolstvo in Ministrstva za izobraževanje, znanost in šport (načeloma) za štiri leta, zaposleni so za poln delovni čas (22 ur). Nenapoteni živijo v eni od evropskih držav, dopolnilni pouk izvajajo nekaj ur na teden, tudi oni so financirani iz Slovenije.

17 Npr. leta 2018 je bilo vseh izseljenih 13.527, od tega 6.595 s slovenskim državljanstvom, med njimi se jih je 45 \% izselilo v Avstrijo ali Nemčijo (prim. Gostič 2019; Vižintin, Lukšič Hacin, Gostič 2020). 
izseljence v Brazilijo tam organizirali nemške šole, je leta 1926 Nemčija podprla idejo duhovnika Božidarja Tensunderna za organizacijo slovenske šole v Nemčiji. V drugi polovici 20. stoletja, leta 1968, je bil prelomen sporazum med Nemčijo in Jugoslavijo, ki je ponovno legaliziral in spodbudil selitvene tokove $v$ Nemčijo iz različnih republik nekdanje skupne države Jugoslavije, tudi iz Slovenije. V Nemčiji so bila ustanovljena številna jugoslovanska in pozneje slovenska (srbska, hrvaška idr.) društva, organizirana je bila slovenska šola, v Nemčijo so bili napoteni slovenski duhovniki. Samostojna Republika Slovenija nadaljuje skrb za ohranjanje slovenske kulture in slovenskega jezika med slovenskimi izseljenkami in izseljenci: v šolskem letu 2019/20 je dopolnilni pouk slovenskega jezika in kulture v 19 evropskih državah poučevalo skupaj 36 učiteljic in učiteljev, od tega šest v Nemčiji.

\section{LITERATURA IN VIRI}

Arlt, Elisabeth, Lorber, Verena (2015). Lebenswege: Slowenische »Gastarbeiterinnen in der Steiermark" = Življenjske poti: Slovenske »zdomske delavke« na avstrijskem Štajerskem. [Laafeld]: Pavelhaus = Pavlova hiša $=$ Pavel house .

Bade, Klaus J. (2005). Evropa v gibanju: Migracije od poznega 18. stoletja do danes. Ljubljana: Založba / ${ }^{*} \mathrm{cf}$.

Bečan, Marjan idr. (2004). Slovenska sobotna šola v Münchnu: 30 let. Ljubljana: Izseljensko društvo Slovenija v svetu, Slovenska župnija v Münchnu.

Brunnbauer, Ulf (2009). Labour Emigration from the Yugoslav Region from the late 19th Century until the End of Socialism: Continues and Changes. Transnational societies, transterritorial politics: Migrations in the (Post-) Yugoslav region: 19th-21st Century (ur. Ulf Brunnbauer). München: R. Oldenbourg, 17-49.

Castles, Stephen, Miller, Mark J. (2009). The Age of Migration: International Population Movements in the Modern World. New York: Guilford Press.

Čepič, Zdenko (2010). Zdomstvo. Migracije in slovenski prostor od antike do danes (ur. Peter Štih, Bojan Balkovec). Ljubljana: Zveza zgodovinskih društev Slovenije, 395-412.

Dopolnilni pouk slovenskega jezika in kulture 2019/20. Zavod Republike Slovenije za šolstvo, Stičišče - slovenščina za Slovence po svetu.

Drnovšek, Marjan (2012). Slovenski izseljenci in Zahodna Evropa v obdobju prve Jugoslavije. Ljubljana: Založba ZRC, ZRC SAZU.

Eick, Simone (2017). Deutsches Auswanderer Haus: Das Buch zum Museum der Aus- und Einwanderung/German Emigration Center: The Museum for Emigration and Immigration Book. Bremerhaven: Dah.

Gostič, Maja (2019). Izkušnje bivanja in dela sodobnih slovenskih izseljencev v Avstriji in Nemčiji. Dve domovini / Two Homelands 50, 217-236.

Japelj Carone, Liza (ur.) (2016). Mi, ki smo odšli: Pričevanja pariških Slovencev povojne generacije. Korenine (posebna številka). Châtillon: Društvo Slovencev v Parizu. 
Kalc, Aleksej, Milharčič Hladnik, Mirjam, Žitnik Serafin, Janja (2020). Doba velikih migracij na Slovenskem. Ljubljana: Založba ZRC, ZRC SAZU.

Knauf, Diethelm (2010). To Govern is to Populate! Migration to Latin America. Living Home: Migration Yesterday and Today (ur. Diethelm Knauf, Barry Moreno). Bremen: ETB, 141-153.

Koordinacija slovenskih društev v južni Nemčiji (2020). Društva, https://koslovenija. wordpress.com/ (25. 2. 2021).

Leggewie, Claus (2010). Germany as an Immigrant Country. Leaving Home: Migration Yesterday and Today (ur. Diethelm Knauf, Barry Moreno). Bremen: ETB, 241-247.

Lukšič Hacin, Marina (2018). Selitvena dinamika slovenskega prostora v zgodovinski perspektivi. Dve domovini / Two Homelands 48, 55-72.

Milharčič Hladnik, Mirjam (2020). Kolektivna izkušnja prebežništva in drugih oblik izseljevanja mladih po drugi svetovni vojni v pisnih, ustnih in drugih avto/biografskih virih. Dve domovini /Two Homelands 51, 151-166, https://doi.org/10.3986/ dd.2020.1.09.

Milharčič Hladnik, Mirjam, Vižintin, Marijanca Ajša (2020). Življenjske zgodbe slovenskih izseljenk, izseljencev: Jana in Franc Kolman - od ekonomske migracije do slovenskega društva. Socialna, gospodarska in kulturna zgodovina slovenskega izseljenstva 1945-1991: Raziskovalno poročilo (ur. Marina Lukšič Hacin, Mirjam Milharčič Hladnik, Damir Josipovič, Aleksej Kalc, Marijanca Ajša Vižintin). Ljubljana: Založba ZRC, 308-340.

Olaj, Jože, Rupnik, Anton (1975). 4. Srečanje slovenskih društev Zapadne Evrope, Bled Essen, 1975. Essen: Kulturno-prosvetno in športno društvo »Bled«.

Pahič, Jože (2020). Slovenska društva v Nemčiji v severni koordinaciji. E-pošta, pridobljena v projektu Socialna, gospodarska in kulturna zgodovina slovenskega izseljenstva (1945-91).

Pogačnik, Marko idr. (1978). 6. Srečanje slov. društev zah. Evrope 1978: Velika kulturna in športna manifestacija slovenskih društev zahodne Evrope 10. 6. 1978 v svetovno znani dvorani Jahrhunderthalle. Frankfurt/M: Slovensko kulturno prosvetno društvo Sava.

Rogelj, Janez (2011). 60 let Slovenske izseljenske matice je enako 40 let vzpona in razvoja ter 20 let opravičevanja in dokazovanja. Rodna gruda: Zbornik ob 60-letnici (ur. Mihael Glavan idr.). Ljubljana: Slovenska izseljenska matica, 17-50.

SKUD Triglav Stuttgart e. V.: 30 let $=$ [30] Jahre: 1970-2000, 2000. Stuttgart: Slowenischer Kultur- und Kunstverein = Slovensko kulturno-umetniško društvo.

Slavec, Ingrid (1982). Slovenci v Mannheimu. Ljubljana: Znanstveni inštitut Filozofske fakultete.

Svetek, Lev (1985). Pravice in dolžnosti: Socialna in ekonomska varnost naših delavcev na tujem. Ljubljana: Delavska enotnost.

Šabjan, Jože (1984). 9. Srečanje slovenskih društev zahodne Evrope: Moravske Toplice '84: Bilten. [S. I.]: Organizacijski odbor 9. srečanja. 
Štrubelj, Zvone (2012). Temna in zamolčana stran slovenskega izseljenstva v Nemčiji: Socialna delavka Doroteja Oblak v pogovoru z dr. Zvonetom Štrubljem. Stuttgart: Slovenska župnija sv. Cirila in Metoda.

Štumberger, Saška (2005). Slovenski selitveni tokovi v Nemčijo in spreminjanje vloge slovenščine. Dve domovini / Two Homelands 22, 95-114.

Tensundern, Božidar (1973). Vestfalski Slovenci: Spomini dušnega pastirja za Slovence Božidarja Tensunderna. Celovec: Družba sv. Mohorja.

Toš, Niko idr. (2014). Vrednote v prehodu IX.: Iz zakladnice socioloških raziskav: Migracije Slovencev (1973-1987) in socialne strukture jugoslovanske družbe (1983-1987). Ljubljana: Fakulteta za družbene vede, IDV-CJMMK; Dunaj: Echoraum.

Vižintin, Marijanca Ajša (2016). Slovenski izseljenci in njihovi potomci v Nemčiji: Dvajset let povezovanja slovenskih organizacij na posvetih. Dve domovini / Two Homelands 43, 157-170.

Vižintin, Marijanca Ajša (2017). Povezovanje Slovencev v Nemčiji na prehodu stoletij in generacij. Raziskovanje slovenskega izseljenstva: Vidiki, pristopi, vsebine (ur. Janja Žitnik Serafin, Aleksej Kalc). Ljubljana: Založba ZRC, ZRC SAZU, 153-169.

Vižintin, Marijanca Ajša, Lukšič Hacin, Marina, Gostič, Maja (2020). Samo visoko izobraženi se izseljujejo. Pa je to res?: Zaključno poročilo. Ljubljana: Založba ZRC.

Werner, Erich Wilhelm (1985). Slovenci v Porurju. Ljubljana: Slovenska izseljenska matica. Wörsdörfer, Rolf (2017). Vom »Westfälischen Slowenen « zum »Gastarbeiter«: Slowenische Deutschland-Migrationen im 19. und 20. Jahrhundert. Paderborn: F. Schöningh.

Zupančič, Jernej (2001). Slovensko izseljenstvo v Evropi po drugi svetovni vojni. Slovensko izseljenstvo: Zbornik ob 50-letnici Slovenske izseljenske matice (ur. Milica Trebše Štolfa, Matjaž Klemenčič). Ljubljana: Združenje Slovenska izseljenska matica, 291-299. 


\section{SUMMARY}

\section{THE BEGINNINGS OF MOTHER TONGUE LESSONS OF SLOVENIAN LANGUAGE AND CULTURE IN GERMANY IN THE TWENTIETH CENTURY Marijanca Ajša VIŽINTIN}

The paper introduces the beginnings of mother tongue lessons of Slovenian language and culture in Germany as one of the consequences of Slovenian migration processes to Germany. The first courses of Slovenian language were organized in 1926 by the German priest Božidar Tensundern for the children of mineworkers who came to work in north Germany from the end of the nineteenth century. A few years later, with the support of the government of the Kingdom of Yugoslavia, eight Slovenian courses were organized in seven German cities, too. These courses were interrupted by World War II and revived after the signing of the bilateral agreement between Germany and Yugoslavia in 1968. The agreement influenced a renewed emigration from Slovenia to Germany, the founding of Slovenian cultural associations, and the organization of Slovenian schools in 1970 and afterward. However, official support from the country of origin is not enough if no individuals are willing to dedicate their private lives to preserving their mother tongue, as the life stories of Jana and Franc Kolman show. They migrated in 1970 and 1971 and established the Slovenian sport-cultural association Drava Augsburg in 1979 to start mother tongue lessons of Slovenian language and culture in Augsburg. Mother tongue lessons of Slovenian language and culture among Slovenian emigrants are still supported today. In 2019/20, the Republic of Slovenia financed thirty-six teachers, six of them in Germany, who taught Slovenian language and culture to Slovenian emigrants and their descendants in nineteen European countries. 